\title{
PEMBERDAYAAN MASYARAKAT DALAM PEMANFAATAN LIMBAH KULIT BUAH NANAS (ananas comosus L. Merr) MENJADI SYRUP KAYA VITAMIN DI KECAMATAN PAYARAMAN
}

\author{
Oleh: \\ Ardiansyah Mahmud (Dosen), \\ Ajeng Wulandari, leni Riska Leliyana, lalu Bintang Wahyuputra \\ Suhadi Maulana, Widia Ningsih \\ Universitas Ahmad Dahlan Yogyakarta
}

\section{Ringkasan}

Kecamatan Payaraman merupakan suatu daerah yang memiliki potensi yang besar dalam bidang perkebunan nanas dan dapat menjadi komoditas unggulan daerah. Penggunaan tanah Payaraman sebagian besar diperuntukan untuk pertanian, padi, nanas, dan karet sedangkan sisanya untuk tanah kering yang merupakan bangunan dan fasilitas-fasilitas lainnya. Dengan luas perkebunan karet yang dimanfaatkan sebagai lahan tanam nanas. Banyaknya hasil perkebunan nanas yang dihasilkan membuat nanas menjadi komoditas unggulan dan mencukupi kebutuhan dan permintaan setempat hal ini mengakibatkan harga nanas dijual dengan harga rendah. Metode yang digunakan dalam pemberdayaan ini pelatihan secara langsung dengan warga. Pembuatan sirup kulit nanas dengan cara memasak kulit nanas, belimbing putih telur dan gula pasir untuk kemudian dikemas dengan botol yang sudah disterilisasi dengan direndam air panas. Dengan pemberdayaan ini diharapkan warga dapat memanfaatkan kulit nanas sebagai meningkatkan asupan vitamin, nilai sehat, ekonomis serta dapat menjadi peluang usaha.

Kata kunci: Pemberdayaan, Limbah, Masyarakat

\begin{abstract}
Payaraman Sub-district is an area that has great potential in the field of pineapple plantations and can be a regional superior commodity. The use of Payaraman land is mostly in the designation for agriculture, Rice, Pineapple, and Rubber while the rest for dry land is a building and other facilities. With the area of rubber plantations that are used as pineapple planting land. The large number of pineapple plantations produced makes pineapple become a pre-eminent commodity and sufficient local demand and demand this results in pineapple prices sold at low prices. The methods used in this empowerment are training directly with citizens. Making pineapple skin syrup by cooking pineapple skin, starfruit, egg whites and granulated sugar and then packed with bottles already sterilized with hot water soaked. With this empowerment is expected citizens can take advantage of pineapple skin as increasing intake of vitamins, healthy value, economical and can be a business opportunity.
\end{abstract}

Keywords: Empowerment, Waste, Community

\section{A. PENDAHULUAN}

\section{Latar Belakang}

Payaraman adalah sebuah Kecamatan di Kabupaten Ogan Ilir, Sumatera Selatan, Indonesia. Kecamatan ini merupakan satu dari enam belas kecamatan yang ada di Kabupaten Ogan Ilir. Kecamatan Payaraman terbentuk sejak tahun 2006 berdasarkan Peraturan Daerah Kabupaten Ogan Ilir Nomor 22 Tahun 2005 yang merupakan hasil dari 
pemekaran Kecamatan Tanjung Batu. Kecamatan Payaraman memiliki luas wilayah administrasi 180, $57 \mathrm{~km} 2$ atau 18.057 hektar. Batas administrasi wilayah Kecamatan Payaraman adalah:

$\begin{array}{ll}\text { Sebelah Utara } & : \text { Kecamatan Tanjung Batu } \\ \text { Sebelah Selatan } & : \text { Kecamatan Rambang Kuang } \\ \text { Sebelah Barat } & : \text { Kecamatan Gelumbang Kabupaten Muara Enim } \\ \text { Sebelah Timur } & : \text { Kecamatan Lubuk Keliat. }\end{array}$

Jumlah Desa dan kelurahan yang ada di Kecamatan Payaraman adalah 11 Desa dan 2 Kelurahan. Desa terluas adalah Desa Tanjung Lalang yang luasnya mencapai 3.055 hektar, Desa Paya Besar mencapai 2.445 hektar, dan Desa tersempit adalah Desa Serikembang II dengan luas 550 hektar dan Desa Tebedak II dengan luas 800 hektar.Kecamatan Payaraman memiliki ketinggian tempat 8 meter diatas permukaan laut, dengan wilayah daratan mencapai $90 \%$ dan wilayah perairan/rawa-rawa mencapai $10 \%$. Derajat keasaman tanah berkisar antara 4,8-6,0.

Nanas merupakan salah satu jenis buah yang mengandung banyak vitamin dan juga bisa berfungsi sebagai obat herbal. Vitamin yang terkandung di dalamnya meliputi vitamin A, vitamin C, kalsium, magnesium, natrium, kalium, fosfor, dekstrosa, sukrosa dan enzim bromelain. Adanya Enzim bromelain dalam buah nanas baik bagi penderita anti radang, membantu memperlancar pencernaan di lambung, menghambat pertumbuhan sel kanker dan mencegah penggumpalan darah. Kandungan serat dalam nanas terbilang tinggi dan cocok sebagai obat bagi penderita sembelit sehingga nanas dapat menjadi obat pencahar bagi mereka yang sulit buang air besar. Nanas juga baik dikonsumsi saat sedang sakit karena dalam nanas terkandung zat-zat yang dapat membantu menyerap obat ke dalam tubuh. Selain itu, buah nanas juga dapat mengangkat sel kulit mati. Salah satu contohnya adalah enzim dalam daun dan buah nanas dapat mengangkat jaringan kulit yang mati akibat luka bakar. Caranya adalah dengan menumbuk beberapa helai daun nanas yang telah dicuci bersih, kemudian dibalurkan pada bagian kulit yang iritasi karena gatal, bisul, atau luka bakar. Radang tenggorokan, perut kembung,

Selain segudang manfaat di atas, ada satu kelebihan lain yang belum banyak diketahui masyarakat luas tentang nanas. Limbah kulit nanas yang tidak bisa dimakan karena terasa gatal di lidah itu ternyata dapat diolah menjadi minuman segar, yaitu bisa diolah menjadi sirup. Pengolahan kulit ini pernah dilakukan oleh mahasiswa KKN Muhammadiyah Untuk Negeri di Kecamatan Payaraman, Ogan Ilir, Sumatera Selatan. Di tangan siswa-siswi di tangan mahasiswa KKN ini kulit nanas mampu mereka sulap menjadi sirup yang bernilai ekonomis tinggi.

Buah nanas (Ananas comosus L. Merr) merupakan salah satu jenis buah yang terdapat di Indonesia, mempunyai penyebaran yang merata. Selain dikonsumsi sebagai buah segar, nanas juga banyak digunakan sebagai bahan baku industri pertanian. Dari berbagai macam pengolahan nanas seperti selai, manisan, sirup, dan lain-lain maka akan didapatkan kulit yang cukup banyak sebagai hasil buangan atau limbah (Rosyidah, 2010).

Pada limbah kulit nanas diduga terdapat senyawa alkaloid, yaitu sebuah golongan senyawa basa bernitrogen yang kebanyakan heterosiklik dan terdapat di tetumbuhan. Hampir seluruh alkaloid berasal dari tumbuhan dan tersebar luas dalam berbagai jenis 
tumbuhan. Secara organoleptik, daun-daunan yang berasa sepat dan pahit, biasanya teridentifikasi mengandung alkaloid. Selain daun-daunan, senyawa alkaloid dapat ditemukan pada akar, biji, ranting, dan kulit kayu. Fungsi alkaloid sendiri dalam tumbuhan sejauh ini belum diketahui secara pasti, beberapa ahli pernah mengungkapkan bahwa alkaloid diperkirakan sebagai pelindung tumbuhan dari serangan hama dan penyakit, pengatur tumbuh, atau sebagai basa mineral untuk mempertahankan keseimbangan ion (Mustikawati, 2006).

\section{Tujuan}

Memberi pengetahuan dan pelatihan dalam pembuatan sirup kulit nanas agar dapat memanfaatkan limbah dan bernilai ekonomis.

\section{B. METODE PELAKSANAAN}

Metode pelaksanaan program pemberdayaan masyarakat melalui peningkatan pengetahuan masyarakat di bidang kewirausahaan, pemasaran dan sirup kulit nanas adalah dengan menggunakan metode pelatihan dan praktek.

\section{HASIL DAN PEMBAHASAN}

Sirup kulit nanas buatan peserta KKN dengan warga sekitar ini rasanya tak kalah dengan sirup produksi pabrikan. Bahkan, lebih unggul karena pembuatannya tanpa bahan pengawet. Semua bahan baku yang diolah menggunakan bahan alami. Proses pembuatannya pun tidak rumit. Setiap orang mungkin bisa mempraktikannya di rumah. Selain kulit nanas sebagai bahan dasar, tentu ada beberapa bahan lain yang ditambahkan dalam proses pembuatannya. Yakni, asem belimbing, gula pasir, kunyit dan jahe. Kemudian, garam dan telur ayam. Semua bahan alami itu nantinya dicampur saat proses pembuatan sirup. Awal mula pembuatannya adalah kulit nanas diiris tipis tipis. Kemudian, dicuci dengan air dan garam hingga bersih. Garam digunakan berfungsi untuk menghilangkan gatal di kulit nanas. Setelah itu, irisan kulit nanas direbus bersama asem belimbing, gula dan kunyit. Setelah mendidih, diangkat dan dinginkan. Bila sirup ingin ada rasa jahenya, saat direbus bisa dicampurkan jahe di dalamnya, atau perasa lain sesuai yang diinginkan.

Dari campuran bahan itu, lalu diremas dengan kain bersih sebagai penyaring hingga keluar sarinya. Air yang keluar itu merupakan sari dari nanas. Langkah selanjutnya, sari nanas direbus kembali hingga mendidih dan tambahkan putih telur ayam secara merata. Putih telur itu berfungsi untuk mengikat sisa kotoran dari perasan nanas. Setelah diaduk aduk gumpalan putih telur disaring kembali hingga menghasilkan perasan air sari nanas yang bersih. Sirup nanas pun siap dihidangkan, dengan ditambah air dingin secukupnya. 


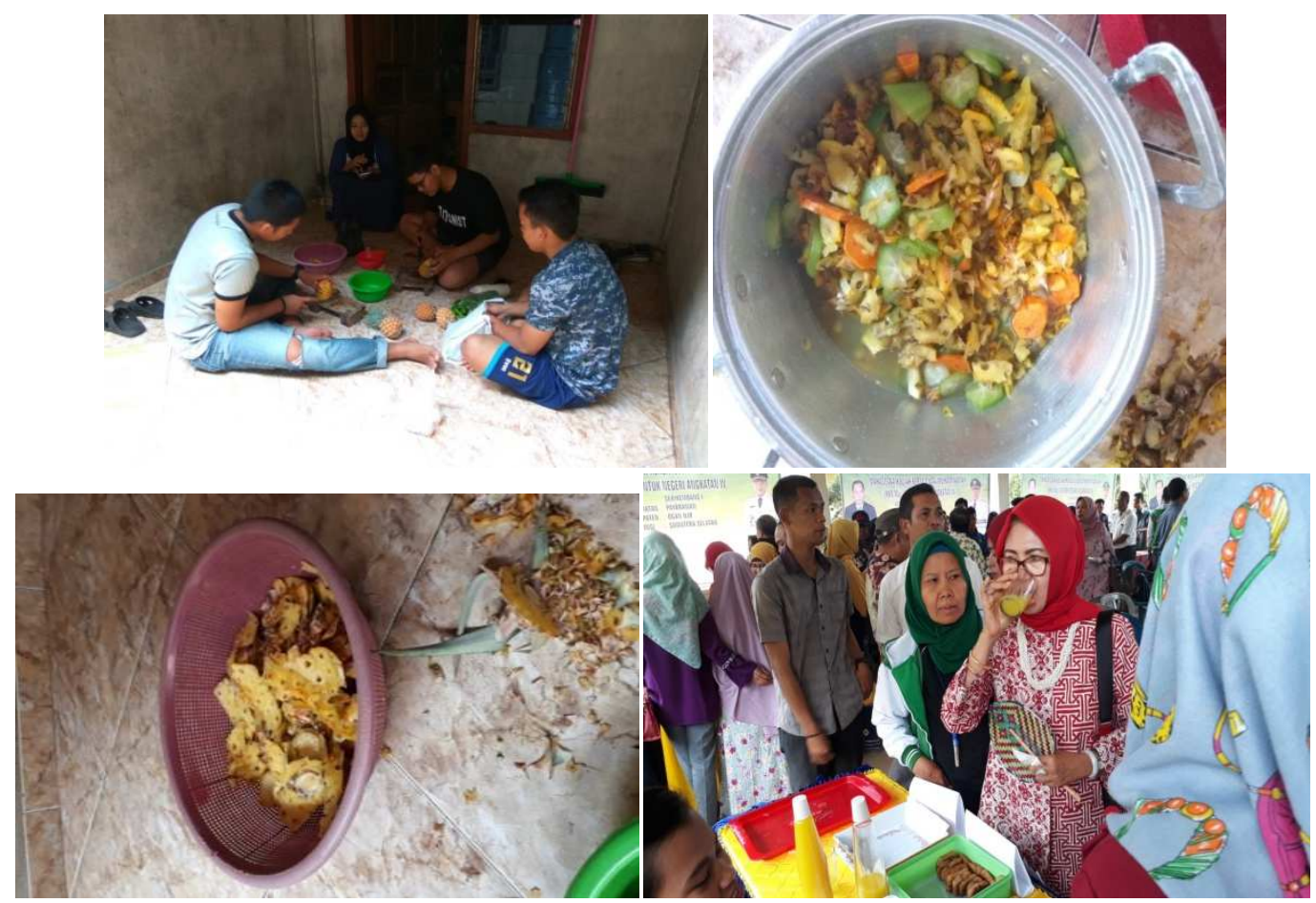

Gambar 1. Proses pembuatan dan hasil syrup kulit nanas

Masalah lain yang juga menjadi kendala bagi petani setempat adalah pengemasan dan pemasaran sirup karena pada saat pembuatan sudah melakukan sterilisasi botol yang digunakan untuk pengemasan akan tetapi syrup tidak bertahan lama hanya 3 sampai 4 hari. Sebagai produk industri rumahan kedua hal ini tentu memerlukan pasar yang tepat. Untuk menjangkau hal ini, panitia lokal sempat mengadakan sebuah seminar dengan Universitas Muhammdiyah Palembang selaku tuan rumah KKN untuk mengadakan seminar UMKM kepada masyarakat Payaraman. Tujuannya agar warga bisa mandiri mengelola hasil alam yang ditanamnya. Dari pelatihan tersebut warga tampak antusias mengikuti seminar dan mengajukan pertanyaan mengenai keluhan yang ditemuinya selama proses pembuatan sirup kulit nanas. Singkat cerita, seminar pelatihan ini berhasil menggerakkan warga untuk memproduksi sirup nanas dan kemudian akan dipasarkan ke wilayah sekitar.

\section{KESIMPULAN}

Dengan adanya pemberdayaan ini diharapkan warga dikecamatan payaraman dapat memanfaatkan Limbah kulit nanas yang banyak dihasillkan untuk dapat dipraketkan secara skala rumah tangga maupun dapat dicanangkan sebagai inovasi produk bagi BUMD maupun warga sekitar yang ingin mengembangkan usaha secara besar agar dapat meningkatkan pendapatan ekonomi, menambah lapangan pekerjaan dan mengurangi limbah yang tidak termanfaatkan. 
Diterbitkan oleh Lembaga Pengabdian kepada Masyarakat

Universitas Ahmad Dahlan Yogyakarta

\section{DAFTAR PUSTAKA}

Badan Pusat Statistik Kabupaten Ogan Ilir, 2016. Kabupaten Ogan Ilir Dalam Angka

Badan Pusat Statistik Kabupaten Ogan Ilir, 2016. Statistik Daerah Kecamatan Payaraman

Mustikawati, I. 2006, Isolasi dan identifikasi senyawa golongan Alkaloid dari daun Ananas Comosus L. Merr., Tesis. Digital Library Universitas Airlangga .Surabaya

Rosyidah, 2010, http://rosyidah.com/2010/06/11/pt -great-giant-pineapple-ggpclumbung-nanas-raksasa-di-indonesia/. Diakses 6 Oktober 2017 
